\title{
Economic evaluation of pregnancy diagnosis in pigs
}

\author{
H. A. M. van der Steen (Animal Breeding Department, Agricultural University, \\ Marijkeweg 40, 6709 PG Wageningen, Netherlands)
}

Received 6 December 1985; accepted 5 March 1986

\begin{abstract}
Pregnancy diagnosis in combination with induction of oestrus in sows diagnosed non-pregnant results in an increase of net return (returns minus costs, labour included) per sow per year. The required reliability of the test is high. Pregnancy diagnosis without induction of oestrus after a negative diagnosis results in a neglectable increase in net return or may even, at a high farrowing percentage, lead to a reduction of net return.
\end{abstract}

Key words: pregnancy diagnosis, economy, pig, sow.

Introduction. Pregnancy diagnosis (US pregnancy test) is being used at several pig producing farms in the Netherlands. The question arises as to what circumstances this results in an increase of net return and how pregnancy diagnosis should be incorporated in herd management.

Methods. The use of pregnancy diagnosis will result in a change of the equilibrium of a herd and hence net return per sow per year. Three systems will be compared by means of model calculations: i) no pregnancy diagnosis, ii) pregnancy diagnosis at 35 days post mating, iii) pregnancy diagnosis at 35 days after mating followed by induction of oestrus in sows diagnosed non-pregnant. In all three systems oestrus detection is assumed to be adequate.

The percentage of sows producing a litter after first mating (farrowing percentage) was varied between 60 and $90 \%$. The sows which do not produce a litter after mating are partioned into four categories. The reference situation (Arts, 1981) was: i) regular early repeat breeders, in oestrus 21 days after mating (35\%); ii) irregular repeat breeders, in oestrus four to six weeks after mating, on average at 35 days (15\%); iii) irregular late repeat breeders, in oestrus between 45 and 115 days after mating, on average at 70 days (20\%); iv) barren and no oestrus at 115 days after mating $(30 \%)$.

The reliability of pregnancy diagnosis can be expressed as the percentage of correct results testing pregnant sows ( $x$, sensitivity) and the percentage of correct results testing barren sows ( $\mathrm{y}$, specificity). The reliability $(\mathrm{x} \mid \mathrm{y})$ was varied between $90 \mid 50$ (unfavourable) and $100 \mid 100$ (optimal).

Returns minus costs, including costs for pregnancy diagnosis and oestrus induction, were calculated based on economic figures under Dutch circumstances, May 1985 (Anon., 1985). Further assumptions were: i) farrowing percentage after a repeat mating as compared to first mating is $10 \%$ lower; ii) $10 \%$ of the sows are culled at the time their litter is weaned; iii) the interval between weaning and first 
Table 1. Differences in net return per sow per year as a result of pregnancy testing versus not testing, with or without induction of oestrus in sows diagnosed non-pregnant.

\begin{tabular}{|c|c|c|c|c|}
\hline \multirow{2}{*}{$\begin{array}{l}\text { Farrowing } \\
\%\end{array}$} & \multicolumn{2}{|c|}{ Without induction of oestrus } & \multicolumn{2}{|c|}{ With induction of oestrus } \\
\hline & $100100^{*}$ & $98 \mid 80$ & $100 \mid 100$ & $98 \mid 80$ \\
\hline 60 & Dlf. 49 & 21 & 79 & 60 \\
\hline 70 & 33 & 10 & 56 & 43 \\
\hline 80 & 15 & -4 & 30 & 22 \\
\hline 90 & -4 & -17 & 2 & 0 \\
\hline
\end{tabular}

* Reliability of pregnancy diagnosis.

oestrus is 10 days; iv) sows are culled after weaning, in case they return to heat after a repeat mating or if they appear to be barren at 120 days after breeding.

Results and discussion. Some of the results are given in Table 1. Pregnancy diagnosis without induction of oestrus after a negative test result is only of economic interest at low farrowing rates. The system with induction of oestrus after a negative test result seems more appropriate. Also for this last system a high reliability of the pregnancy diagnosis is needed.

The management system would then include: i) oestrus detection; ii) pregnancy test once a week at about 5 weeks after breeding; iii) induction of oestrus in sows diagnosed non-pregnant.

Induction with a PMS/HCG compound does not affect the pregnant sows. Barren sows which come in heat after induction can be bred or culled. All non-reacting sows, including the pregnant ones, are kept, as we do not know which sows are pregnant and which ones are barren.

With the most likely parameters in practice: a reliability of pregnancy diagnosis of $98 \mid$ a farrowing percentage of $80 \%, 35 \%$ of non-pregnant sows showing a spontaneous oestrus at approximately 21 days after breeding and $70 \%$ of the barren sows reacting on oestrus induction after pregnancy diagnosis, the percentage of sows which are kept and do not farrow amounts to $5.00 \%$. This group consists of late repeat breeders $(1.67 \%)$ and sows which appear to be barren at 115 days after breeding (3.33\%, including sows with abortion).

\section{References}

Arts, J. A. M., 1981. Drachtigheidsonderzoek bij varkens: een economische evaluatie. IVO-rapport B. 176 .

Anonymous, 1985. Biggenprijzenschema voor Zuid-Nederland, mei 1985.

This synopsis is based on a report entitled 'Economische evaluatie van drachtigheidscontrole bij varkens', Animal Breeding Department, Agricultural University, Wageningen, 1985 . ii +20 pp., 13 figs., 3 tables, 4 refs. Dutch, English summary and captions.

Available as paper copy (order R052P, $f 20$ including postage) or microfiche (order R052M, f 12.50 including postage) at: NARD, clo Pudoc, P.O. Box 4, 6700 AA Wageningen, Netherlands (telex 45015 blhwg). 